\title{
Breast and Cervical Cancer Screening: Impact of Health Insurance Status, Ethnicity, and Nativity of Latinas
}

\author{
Michael A. Rodríguez, $M D, M P H^{1}$ \\ Lisa M. Ward, MD, MScPH ${ }^{2}$ \\ Eliseo J. Pérez-Stable, $M D^{3}$
}

'Department of Family Medicine at the David Geffen School of Medicine, University of California, Los Angeles, Los Angeles, Calif

${ }^{2}$ Department of Obstetrics and Gynecology, Center for Women's Health, University of

California, Davis, Sacramento, Calif

${ }^{3}$ Division of General Internal Medicine, Department of Medicine, Medical Effectiveness Research Center for Diverse Populations, Center for Aging in Diverse Communities, Comprehensive Cancer Center, University of California, San Francisco, San Francisco, Calif

Conflicts of interest: none reported

\section{CORRESPONDING AUTHOR}

Michael A. Rodríguez, MD David Geffen School of Medicine at UCLA Oppenheimer Tower, Suite 1800 10880 Wilshire Blvd

Los Angeles, CA 90024

mrodriguez@mednet.ucla.edu

\begin{abstract}
PURPOSE Although rates of cancer screening for Latinas are lower than for nonLatina whites, little is known about how insurance status, ethnicity, and nativity interact to influence these disparities. Using a large statewide database, our study examined the relationship between breast and cervical cancer screening rates and socioeconomic and health insurance status among foreign-born Latinas, US-born Latinas, and non-Latina whites in California.
\end{abstract}

METHODS Data from the1998 California Women's Health Survey (CWHS) were analyzed $(n=3,340)$ using multiple logistic regression models. Utilization rates of mammography, clinical breast examinations, and Papanicolaou (Pap) smear screening among foreign-born Latinas, US-born Latinas, and non-Latina whites were the outcome measures.

RESULTS Foreign-born Latinas had the highest rates of never receiving mammography, clinical breast examinations, and Pap smears $(21 \%, 24 \%, 9 \%$, respectively) compared with US-born Latinas (12\%, $11 \%, 7 \%$, respectively) and non-Latina whites $(9 \%, 5 \%, 2 \%$, respectively). After controlling for socioeconomic factors, foreign-born Latinas were more likely to report mammography use in the previous 2 years and Pap smear in the previous 3 years than non-Latina whites. Lack of health insurance coverage was the strongest independent predictor of low utilization rates for mammography (odds ratio $[\mathrm{OR}]=2.05 ; 95 \%$ confidence interval $[\mathrm{Cl}], 1.53-2.76)$, clinical breast examinations $(\mathrm{OR}=2.29 ; 95 \% \mathrm{Cl}, 1.80-2.90)$ and Pap smears $(\mathrm{OR}=2.89 ; 95 \% \mathrm{Cl}, 2.17-3.85$.)

CONCLUSIONS Breast and cervical cancer screening rates vary by ethnicity and nativity, with foreign-born Latinas experiencing the highest rates of never being screened. After accounting for socioeconomic factors, differences by ethnicity and nativity are reversed or eliminated. Lack of health insurance coverage remains the strongest predictor of cancer screening underutilization.

Ann Fam Med 2005;3:235-241. DOI: 10.1370/afm.291.

\section{INTRODUCTION}

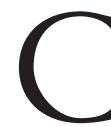

ancer is the second leading cause of death in the United States. ${ }^{1}$

Tragically, Latinas in the United States have greater proportions ment, and worse breast cancer survival outcomes. ${ }^{4,5}$ Latinas also experience twice the incidence of cervical cancer compared with non-Latina whites. ${ }^{6}$ These disparities stem in part from infrequent screening practices for these cancers. Previous studies suggest that Latinas face added challenges in gaining access to needed preventive health services compared with nonLatina whites because they are less educated, ${ }^{7-9}$ have lower incomes, ${ }^{7.9}$ have lower rates of health insurance coverage, ${ }^{9-14}$ and have limited English proficiency. ${ }^{15}$ Studies that examined utilization of cancer screening services by nativity suggest that immigrants are less likely to receive a Papanicolaou 
(Pap) smear. ${ }^{16,17}$ Other studies, however, either suggest that birthplace is not a significant predictor of cancer screening utilization ${ }^{18-20}$ or that foreign-born status increases the chances of cancer screening utilization. ${ }^{21}$ The conflicting conclusions among these studies may be accounted for by differences in definitions of screening, lack of adjustments for predictive variables, and inclusion of heterogeneous Latina groups.

In addition, ethnicity, nativity, and health insurance status may interact in complex ways to influence access to appropriate preventive services. Understanding the mechanisms of these interactions will help inform interventions to reduce disparities in health care by increasing screening rates for breast and cervical cancer among Latinas. The Institute of Medicine has also recommended that data collection include subpopulations within ethnic populations, because these data will provide a better understanding on variations in care based on race and ethnicity. ${ }^{22}$ Latinas are one of the largest and fastest growing populations in the United States; efforts to reduce disparities in screening rates for cancer among Latinas may be more effective if we more fully understand how overlapping characteristics may contribute to subgroups that are less likely to be screened. We conducted this study to help fill our knowledge gap about subpopulations of Latinas, those born in and outside the United States, by examining the relationship between rates of cancer screening utilization and health insurance coverage among foreign- and US-born Latinas compared with non-Latina whites using a statewide population-based California database.

\section{METHODS}

\section{Data Source}

This study used data from the 1998 California Women's Health Survey (CWHS), a cross-sectional household telephone survey in which Californian women aged 18 years and older were asked about their healthrelated behaviors and attitudes. The survey instrument included questions from previously conducted national or statewide surveys when ever possible.

A random digit dialing process selected telephone numbers. All women who were 18 years and older within a household were considered eligible to participate in the survey. Eligible household participants were contacted or systematically called again when there was no answer or a busy signal. The survey instrument was validated for use among Spanish-speakers, and interviewers were trained to administer the survey in multiple languages. Forty percent of the interviewing staff was fluent in Spanish so that interviews could be conducted in Spanish, as needed; more than $75 \%$ of foreign-born Latinas completed the survey in Spanish.
Data from the CWHS were weighted to make respondents statistically representative of all women in California according to age and race in accordance with the 1990 California population.

\section{Questionnaire Items}

Ethnicity was determined by the respondent's reply to whether she was of Hispanic origin. Nativity status was established by asking about country of birth. The degree of poverty was categorized as an income of $100 \%$ or less, between $101 \%$ and $200 \%$, and greater than $200 \%$ of poverty-level income. Poverty was defined as an annual income of less than $200 \%$ of the federal poverty-level according to the number of family members and the total household income The highest grade of school completed (less than a high school education, completion of high school, or education beyond high school) determined education level. Employment status was ascertained by asking whether the respondent was currently employed fulltime, employed part-time, self-employed, out of work, a homemaker, a student, retired, or unable to work. Employment status was then dichotomized into fulltime employment vs not full-time employment. Women were classified as uninsured if they lacked any source of health insurance at the time of the survey. Marital status was categorized into married and not married. Childbirth in the previous 3 years was determined by asking women whether they had children and the dates of their children's birth.

For breast cancer screening, all respondents aged 40 years and older were asked whether they ever had a mammogram and clinical breast examination, and the length of time since their last examination. Recent breast cancer screening was defined as receiving a mammogram and clinical breast examination in the previous 2 years.

For cervical cancer screening, all respondents were asked whether they ever had a Pap smear and how long it had been since their last examination. Recent cervical cancer screening was defined as having a Pap smear in the previous 3 years

\section{Statistical Analysis}

We used $\chi^{2}$ tests to determine the relationship between explanatory variables and outcomes of interest. Differences in cancer screening utilization between ethnic and nativity groups were determined after controlling for health insurance status.

We used multiple logistic regression models to examine the relationship between all explanatory variables and outcomes of interest. Three models were evaluated for differences in screening rates: mammography examinations in the preceding 2 years, clinical 
breast examinations in the preceding 2 years, and Pap tests in the preceding 3 years. Spanish language was eliminated from each model because of the strong colinearity with nativity. Logistic regression was used to investigate interaction effects between nativity, income, education, and employment with childbirth, ethnicity, and outcomes of interest. The overall model fit was tested using the Wald statistic. Data were analyzed using SAS for Windows, version 8.2 (2003).

\section{RESULTS}

\section{Descriptive Findings}

The overall survey response rate was $70 \%$, which reflects the proportion of contacted eligible households that resulted in a completed interview. Table 1 displays demographic and socioeconomic characteristics for foreign-born Latinas, US-born Latinas, and non-Latina whites $(\mathrm{n}=3,340)$. Of the women surveyed, $510(15 \%)$ were foreign-born Latinas, 341 (10\%) were US-born Latinas, and 2,489 (75\%) were non-Latina whites.

Foreign-born (mean age 38 years, standard deviation (SD) 12 years) and US-born Latinas (mean age 37 years, SD 15 years) were younger than non-Latina whites (mean age of 46 years, SD 19 years). Foreign-

\begin{tabular}{|c|c|c|c|}
\hline Characteristics & $\begin{array}{c}\text { Foreign-Born } \\
\text { Latinas } \\
\% \text { (n) }\end{array}$ & $\begin{array}{l}\text { US-Born } \\
\text { Latinas } \\
\% \text { (n) }\end{array}$ & $\begin{array}{c}\text { Non-Latina } \\
\text { Whites } \\
\% \text { (n) }\end{array}$ \\
\hline \multicolumn{4}{|l|}{ Age, y } \\
\hline $18-39$ & $64(328)$ & $65(223)^{\dagger}$ & $44(1,105)$ \\
\hline $40-59$ & $26(131)$ & $20(70)$ & $30(736)$ \\
\hline$\geq 60$ & $10(51)$ & $14(49)$ & $26(648)$ \\
\hline \multicolumn{4}{|l|}{ Income level* } \\
\hline$\leq 100 \%$ poverty & $56(250)$ & $29(93)$ & $10(223)$ \\
\hline $101 \%-200 \%$ poverty & $29(129)$ & $21(66)$ & $19(432)$ \\
\hline$>200 \%$ poverty & $15(66)$ & $50(159)$ & $71(1,620)$ \\
\hline \multicolumn{4}{|l|}{ Educational level* } \\
\hline$<$ High school & $62(317)$ & $21(71)$ & 8 (193) \\
\hline Completed high school & $18(92)$ & $31(106)$ & $26(645)$ \\
\hline > High school & $20(100)$ & $48(164)$ & $66(1,651)$ \\
\hline Employment, full-time & $32(163)$ & $38(130)$ & $35(883)$ \\
\hline Insurance status, ${ }^{*}$ uninsured & $44(213)$ & $19(57)$ & $10(198)$ \\
\hline Current marital status, married & $56(286)$ & $45(154)$ & $53(1,325)$ \\
\hline Birth in the last 3 years* & $30(120)$ & $29(72)$ & $20(274)$ \\
\hline Spanish language interview* & $76(386)$ & $5(16)$ & N/A \\
\hline Total, $\mathrm{n}$ & 510 & 341 & 2,489 \\
\hline
\end{tabular}

Note: Data derived from the 1998 California Women's Health Survey, weighted to make respondents statistically representative of all women in California according to age and race in accordance with the 1990 California population.

$\mathrm{NA}=$ not applicable

* $\chi 2$ tests determined differences were significant, $P \leq .01$ for each characteristic. † Proportions in each age group do not equal $100 \%$ due to rounding. born Latinas were more likely to be poor, have fewer years of education, be uninsured, be married, and have experienced childbirth within the previous 3 years compared with non-Latina white women.

The proportions of women receiving mammography, clinical breast examination, and Pap smear by ethnicity are featured in Table 2. Foreign-born Latinas had significantly lower rates of recent mammography compared with non-Latina whites. Foreign-born Latinas also had the highest rates of never having had a mammogram compared with both US-born and non-Latina whites. Regarding clinical breast examination, foreignborn and US-born Latinas had significantly lower rates of recent screening as well as higher rates of never having had a clinical breast examination than non-Latina whites. As for Pap smears, foreign-born Latinas and US-born Latinas were also more likely to have never had a Pap smear compared with non-Latina whites.

Cancer screening utilization rates among ethnic groups were assessed while stratifying by insurance status. No statistically significant differences were found in mammography utilization rates when controlling for health insurance status among women of different ethnicity or nativity groups. Differences in clinical breast examination utilization, however, were noted.

Among insured women, foreignborn Latinas and US-born Latinas more frequently lacked screening compared with non-Latina whites $(26 \%, 29 \%$, and $17 \%$, respectively) $(P \leq .01)$. Among uninsured women, $53 \%$ of foreign-born Latinas, $67 \%$ of US-born Latinas, and $50 \%$ of non-Latina white women had not received a clinical breast examination in the last 2 years $(P \leq .01)$. Significant differences in Pap smear utilization rates by ethnicity and nativity persisted when stratifying by insurance data. Among women with health insurance coverage, $13 \%$ of foreign-born Latinas, $16 \%$ of US-born Latinas, and 15\% of non-Latina white women reported that they had not had a screening in the previous 3 years $(P \leq .01)$. Among uninsured women, a lack of screening was evident; $24 \%$ of foreign-born and $36 \%$ of USborn Latinas, as well as ??\% of non-Latina white women, had not received this examination in the previous 3 years $(P \leq .01)$. 


\begin{tabular}{|c|c|c|c|}
\hline $\begin{array}{l}\text { Cancer Screening } \\
\text { Examination }\end{array}$ & $\begin{array}{l}\text { Foreign-Born } \\
\text { Latina } \\
\%(n)\end{array}$ & $\begin{array}{l}\text { US-Born } \\
\text { Latina } \\
\%(n)\end{array}$ & $\begin{array}{l}\text { Non-Latina } \\
\text { Whites } \\
\%(n)\end{array}$ \\
\hline \multicolumn{4}{|l|}{ Mammography } \\
\hline Recently screened (within 2 y) & $66(147)^{\dagger}$ & 75 (119) & $78(1168)$ \\
\hline Never screened ${ }^{1}$ & $21(48)^{\dagger \neq}$ & $12(20)$ & $9(132)$ \\
\hline \multicolumn{4}{|l|}{ Clinical breast examination } \\
\hline Recently screened (within 2 y) ${ }^{1}$ & $66(148)^{\dagger}$ & $73(117)^{\S}$ & $82(1235)$ \\
\hline Never screened ${ }^{1}$ & $24(53)^{+11}$ & $11(18)^{\S}$ & $5(69)$ \\
\hline \multicolumn{4}{|l|}{ Papanicolaou smear } \\
\hline Recently screened (within 3 y) & $85(559)$ & $85(378)$ & $85(2021)$ \\
\hline Never screened ${ }^{1}$ & $9(59)^{\dagger}$ & $7(29)^{\S}$ & $2(63)$ \\
\hline \multicolumn{4}{|c|}{$\begin{array}{l}\text { Note: Data derived from the } 1998 \text { California Women's Health Survey weighted to make respondents statistically } \\
\text { representative of all women in California according to age and race in accordance with the } 1990 \text { California popu } \\
\text { lation. Percentages may not total 100\% due to missing responses. }\end{array}$} \\
\hline $\begin{array}{l}\text { * P values for utilization rates between } \\
\text { † Foreign born Latina vs non-Latina Whi } \\
\text { † Foreign born Latina vs US-born Latina, } \\
\text { § US-born vs non-Latina White } \\
\text { |l Foreign-born Latina vs US-born Latina. }\end{array}$ & $\begin{array}{l}\text { and nativity groups a } \\
0.05 \text {. }\end{array}$ & gnificant, $P<.0$ & \\
\hline
\end{tabular}

Six variables were significant in a model of no recent Pap smear utilization after adjusting for other predictor variables. Lack of health insurance coverage was the strongest predictor of no recent Pap smear $(\mathrm{OR}=2.89 ; 95 \% \mathrm{CI}$, 2.17-3.85). Poverty predicted lack of Pap smear in the previous 3 years $(\mathrm{OR}=1.58,95 \% \mathrm{CI}$, 1.23-2.03) as did being unmarried $(\mathrm{OR}=1.39,95 \% \mathrm{CI}, 1.12-1.72)$. In contrast, Foreign-born Latina status $(\mathrm{OR}=0.59,95 \% \mathrm{CI} 0.41$ 0.84 ), full-time employment (OR $=0.66 ; 95 \% \mathrm{CI}, 0.52-0.84)$, and recent childbirth $(\mathrm{OR}=0.30$, 95\% CI, 0.20-0.45) predicted an increase in recent Pap smear utilization, as did childbirth in the previous 3 years $(\mathrm{OR}=0.30,95 \%$ CI 0.20-0.45).

\section{Multivariate Analysis}

After using logistic regression (Table 3), 6 variables remained significantly associated with no recent mammogram. Lack of health insurance strongly predicted no recent mammogram (odds ratio $[\mathrm{OR}]=2.05 ; 95 \%$ confidence interval $[\mathrm{CI}] 1.53-2.76)$. Poverty $(\mathrm{OR}=$ $1.69,95 \% \mathrm{CI}, 1.33-2.14)$ and being unmarried $(\mathrm{OR}=$ $1.35 ; 95 \% \mathrm{CI}, 1.11-1.63)$ also predicted lack of recent mammogram. Foreign-born Latina status was protective for recent mammography utilization $\left(\mathrm{OR}=0.60_{\text {; }}\right.$ $95 \% \mathrm{CI}, 0.45-0.81)$, as was full-time employment (OR $=0.79 ; 95 \% \mathrm{CI}, 0.65-0.95)$. Age was weakly protective for mammography utilization $(\mathrm{OR}=0.90 ; 95 \% \mathrm{CI}$ 0.89-0.91).

After adjusting for factors associated with recent clinical breast examination, 6 variables remained predictive of no recent clinical breast examination. Lack of health insurance coverage was the strongest predictor of no recent clinical breast examination $(\mathrm{OR}=2.29$; $95 \% \mathrm{CI}, 1.80-2.90)$. Likewise, poverty independently predicted lack of recent screening $(\mathrm{OR}=2.12 ; 95 \%$ $\mathrm{CI}, 1.71-2.64$ ). Low educational attainment (less than high school education) was predictive of no recent clinical breast examination as well $(\mathrm{OR}=1.49 ; 95 \%$ $\mathrm{CI}, 1.16-1.92)$. US-born Latinas and unmarried women had similar likelihoods of no recent clinical breast examination $(\mathrm{OR}=1.38,95 \% \mathrm{CI} 1.06-1.81$; and $\mathrm{OR}=$ $1.39 ; 95 \%$ CI 1.16-1.68, respectively). In contrast, fulltime employment predicted an increased likelihood of receiving clinical breast examination in the last 2 years $(\mathrm{OR}=0.66,95 \% \mathrm{CI} 0.54-0.81)$.

\section{DISCUSSION}

Closing the gap in ethnic disparities for access and health outcomes is a top priority for this nation. This study found significant disparities in unadjusted rates of breast and cervical cancer screening across ethnicity and nativity. Foreign-born Latinas had the highest rates of never being screened with mammography, clinical breast examinations, and Pap smears when compared with US-born Latinas and non-Latina whites. Additionally, foreign-born Latinas had the lowest rates of recent breast cancer screening among all 3 groups. This underscores the importance of examining Latino subgroups to better understand the role of ethnicity in preventive health services utilization. ${ }^{22}$ Furthermore, it shows that foreign-born Latinas are a group that may benefit from public health efforts tailored to improve utilization of cancer screening services.

As expected, our results also showed the vital roles that health insurance and socioeconomic status play in cancer screening for breast and cervical cancer. When stratifying by insurance status, all ethnic and native groups showed an $11 \%$ to $48 \%$ decrease in the percentage of uninsured women receiving timely screenings. Because a greater proportion of foreign-born Latinas are uninsured compared with the other subgroups, they are at greater risk of lacking timely cancer screening. This study mirrors national surveys suggesting that those who are poor, ${ }^{7,8}$ less educated ${ }^{8,23}$ and uninsured ${ }^{7,24}$ are at a greater risk for underutilization of services that screen for breast and cervical cancer. Although increased 
Table 3. Adjusted Odds Ratios of the Association Between Explanatory Variables and Lack of Recent Papanicolaou Smear, Mammography, and Clinical Breast Examination ( $\mathrm{N}=3,340)$

\begin{tabular}{|c|c|c|c|c|c|c|}
\hline \multirow[b]{2}{*}{ Variable } & \multicolumn{2}{|c|}{$\begin{array}{c}\text { Mammography Examination } \\
\text { in Previous } 2 \text { Years }\end{array}$} & \multicolumn{2}{|c|}{$\begin{array}{c}\text { Clinical Breast Examination } \\
\text { in Previous } 2 \text { Years }\end{array}$} & \multicolumn{2}{|c|}{$\begin{array}{l}\text { Papanicolaou Smear } \\
\text { in Previous } 3 \text { Years }\end{array}$} \\
\hline & Adjusted OR & $95 \% \mathrm{Cl}$ & Adjusted OR & $95 \% \mathrm{Cl}$ & Adjusted OR & $95 \% \mathrm{Cl}$ \\
\hline Foreign-born Latina² & 0.60 & $0.45-0.81$ & 1.19 & $0.90-1.56$ & 0.59 & $0.41-0.84$ \\
\hline US-born Latina & 0.91 & $0.69-1.20$ & 1.38 & $1.06-1.81$ & 1.11 & $0.80-1.54$ \\
\hline Uninsured* & 2.05 & $1.53-2.76$ & 2.29 & $1.80-2.90$ & 2.89 & $2.17-3.85$ \\
\hline $\begin{array}{l}\text { Less than high school } \\
\text { education }\end{array}$ & 1.20 & $0.89-1.61$ & 1.49 & $1.16-1.92$ & 1.37 & $1.01-1.86$ \\
\hline$\leq 200 \%$ poverty* & 1.69 & $1.33-2.14$ & 2.12 & $1.71-2.64$ & 1.58 & $1.23-2.03$ \\
\hline Employment full-time & 0.79 & $0.65-0.95$ & 0.66 & $0.54-0.81$ & 0.66 & $0.52-0.84$ \\
\hline Age $5 y^{*}$ & 0.90 & $0.89-0.91$ & 1.00 & $0.99-1.01$ & 1.02 & $1.02-1.03$ \\
\hline Unmarried* & 1.35 & $1.11-1.63$ & 1.39 & $1.16-1.68$ & 1.39 & $1.12-1.72$ \\
\hline Childbirth in last $3 y^{*}$ & - & - & - & - & 0.30 & $0.20-0.45$ \\
\hline \multicolumn{7}{|c|}{$\begin{array}{l}\text { Note: Data derived from the } 1998 \text { California Women's Health Survey weighted to make respondents statistically representative of all women in California according to age } \\
\text { and race in accordance with the } 1990 \text { California population. Papanicolaou data include all women, whereas mammography and clinical breast examination data include } \\
\text { women } \geq 40 \text { years of age. }\end{array}$} \\
\hline \multicolumn{7}{|c|}{$\mathrm{OR}=$ odds ratio; $\mathrm{Cl}=$ confidence interval. } \\
\hline \multicolumn{7}{|c|}{$\begin{array}{l}\text { * Models are adjusted for age in 5-year intervals, birthplace/ethnicity (US white as referent vs Latina-foreign and Latina US), poverty level ( } \leq 200 \% \text { vs }>200 \% \text { ), education } \\
\text { (more vs less than high school graduate), employment (not full-time vs full-time), insurance (any insurance vs none), marital status (married vs not married), and giving birth } \\
\text { (in the last } 3 \text { years vs not). }\end{array}$} \\
\hline
\end{tabular}

Latina cancer screening rates have been reported in the past decade, ${ }^{25}$ this study shows that Latinas still remain at risk of underutilizing preventive screening services, and foreign-born Latinas are at an even greater risk for substandard utilization of breast and cervical cancer screening services. Lack of health insurance remains a serious obstacle that needs to be addressed to improve utilization of cancer screening services for all uninsured women. Given the disproportionate rates of uninsurance, low income, and low educational attainment among foreign-born Latinas, culturally and linguistically appropriate screening interventions for this population may help reduce ethnic health disparities as well.

This study contributes new knowledge on the impact of ethnicity and nativity as a predictor of cancer screening utilization. Among Latinos in Texas and California, higher levels of acculturation were associated with more timely utilization of cervical and breast cancer screening. ${ }^{16,26,27}$ Studies that included both socioeconomic factors and ethnicity as explanatory variables reported that socioeconomic factors, such as poverty, educational attainment, and health insurance status, predicted utilization rates to a much greater extent than ethnicity. ${ }^{9,17,23,26}$ Nevertheless, in one study foreign-born status was still predictive of underutilization for cancer screening. ${ }^{19}$ While our study confirms the association between socioeconomic status and utilization rates, a surprising finding was that foreign-born status was positively associated with screening in the model of Pap smear and mammography utilization after adjusting for confounding variables. The difference in results between our study and previous studies may be attributed to our focus on the Latinas in California, which decreased the heterogeneity and increased the likelihood of finding differences.

The findings in this study are also consistent with literature showing that foreign-born women have better than expected outcomes in a variety of areas when compared with non-Latina whites after adjusting for socioeconomic status. Despite limitations in accessing health care, immigrants to the United States have lower all-cause and cause-specific mortality rates. ${ }^{28}$ In the year 2000, California foreign-born Latinas had a life expectancy of 84.3 years, whereas US-born Latinas had a life expectancy of 82.6 years, and overall female life expectancy for non-Latina whites was 80.1 years. ${ }^{29}$ Similarly, Latinas give birth to relatively fewer low-birth-weight babies compared with white nonLatinas despite socioeconomic disadvantages and lower rates of prenatal care. ${ }^{30-31}$ It has been suggested that minority women may experience increased access to screening services through programs linked to income and a lack of health insurance coverage. ${ }^{7}$ In a previous study conducted by Pérez-Stable et al, birthplace was not a significant predictor of obtaining cancer screening tests. This finding suggests that being involved in a health care plan may diminish differences in preventive services utilization for foreign-born Latinas. ${ }^{18}$ This study is consistent with our findings that show, when adjusted for insurance status and other variables, foreign-born Latinas were actually more likely to report cancer screening utilization. Nevertheless, delays in breast cancer diagnosis among Latinas ${ }^{2}$ and higher rates of cervical cancer ${ }^{6}$ suggest that screening levels remain 
inadequate. These data provide support for additional research on Latino subpopulations to identify resiliency factors that may benefit other groups, as well as provide support for policy efforts to cover all US residents with health insurance, regardless of legal status.

Although foreign-born Latinas were more likely to receive mammography and Pap smear screenings after adjusting for insurance status and other socioeconomic factors, US-born Latinas were not. Some literature suggests that having strong traditional ethnic belief systems may explain the differences observed between nativity groups. For example, Mexican-American women who held strong traditional Mexican family values were more likely to receive mammograms. ${ }^{27}$ Foreign-born Latinas may hold stronger beliefs in their susceptibility to and in the seriousness of breast can$\operatorname{cer}^{31}$ and thus may be more motivated to receive breast cancer screenings. In contrast, foreign-born women may also have more fatalistic views toward health, which could discourage them from seeking preventive services. ${ }^{16,32}$ To prevent misconceptions stemming from identification of Latinos as a homogeneous group regarding preventive health care behavior, ${ }^{33}$ more work is needed to investigate the factors motivating foreignborn Latinas to obtain screenings. Diverse public health strategies will likely be needed to improve utilization rates for screening services among Latinas.

This study has several limitations. Telephone surveys exclude households that lack telephone service; therefore, this limitation may have disproportionately affected those foreign-born Latinas, functionally impaired persons, and residents of rural areas who are more likely to lack a telephone. ${ }^{21}$ Telephone surveying may also overrepresent women living in large households. This characteristic may be associated with ethnicity, nativity, and socioeconomic status factors found to be significant in this study. In addition, self-reported answers are subject to recall and social-desirability bias, which may lead to higher estimates of screening, however, overestimates in self-reported screening rates do not appear to differ much by Latino ethnicity. ${ }^{34,35}$ Also, the sensitive nature of nativity may exacerbate misclassification bias and reduce completion and response rates. Misclassification of birthplace can bias results to the null, resulting in underestimation of the actual differences found in the study.

The unequal burden of breast and cervical cancer among Latinas is an important dilemma and challenge for our nation. The high uninsurance rates among foreign-born Latinas may explain some of the disparity. The results of this study suggest that if we improve access to care for foreign-born Latinas, they will use cancer screening services appropriately. The outcomes also illustrate the heterogeneity of Latinas and the importance of including nativity when conducting analysis of immigrant groups, because these women have an unequal burden of factors to be addressed before utilization of cancer screening services can improve. Specific programs that may help include culturally and linguistically appropriate delivery of care, as well as public health messages to increase awareness of publicly funded programs to prevent cancer. These findings also provide new insight into the needs of poor, uninsured non-Latina white women. Recent trends in health policy that curtail state and national funding of social services for the medically underserved in an attempt to reduce budget deficits may adversely affect access for all women. It is important to advocate for policies that ensure access to high-quality cancer screening and treatment for all patients.

To read commentaries of to post a response to this article, see it online at http://www.annfammed.org/cgi/content/full/3/3/235.

Key words: Breast neoplasms; cervix neoplasms; prevention $\&$ control, Hispanic Americans; delivery of health care; minority groups

Submitted March 16, 2004; submitted, revised December 10, 2004; accepted December 23, 2004.

Funding support: California Program on Access to Care, grant P30AG15272 under the Resource Centers for Minority Aging Research program by the National Institute on Aging, the National Institute of Nursing Research, the National Center on Minority Health and Health Disparities, and the National Institutes of Health. This study was also supported by a grant from a National Cancer Institute (NCI) Special Populations Network grant for Redes en Acción (U01CA86117).

Acknowledgments: We gratefully acknowledge Jill Gurvey for her analytical and programming assistance and Ginny Gildengorn for her statistical consultation. We also thank Kirsten La for her assistance with the manuscript.

\section{References}

1. US Department of Health and Human Services. Healthy People 2010. 2nd ed. With Understanding and Improving Health and Objectives for Improving Health. 2 vols. Washington, DC: U.S. Government Printing Office; 2000.

2. Hedeen AN, White E. Breast cancer size and stage in Hispanic American women, by birthplace: 1992-1995. Am J Public Health. 2001;91:122-125.

3. Menck HR, Mills PK. The influence of urbanization, age, ethnicity, and income on the early diagnosis of breast carcinoma. Cancer. 2001;92:1299-1304.

4. Shavers VL, Harlan LC, Stevens JL. Racial/Ethnic variations in clinical presentation, treatment, and survival among breast cancer patients under age 35. Cancer. 2003;97:134-417.

5. Li Cl, Malone KE, Daling JR. Differences in breast cancer stage, treatment, and survival by race and ethnicity. Arch Intern Med. 2003; 163:49-56.

6. Centers for Disease Control and Prevention. Invasive cervical cancer among Hispanic and non-Hispanic women - United States - 19921999. 2002. Available at: http://www.cdc.gov/mmwr/preview/ mmwrhtml/mm5147a2.htm. 
7. Calle EE, Flanders WD, Thun MJ, Martin LM. Demographic predictors of mammography and Pap smear screening in US women. Am J Public Health. 1993;83:53-60.

8. Frazier EL, Jiles RB, Mayberry R. Use of screening mammography and clinical breast examinations among Black, Hispanic, and White women. Prev Med. 1996;25:118-125.

9. Zambrana RE, Breen N, Fox SA, Gutierrez-Mohammed ML. Use of cancer screening practices by Hispanic women: analyses by subgroup. Prev Med. 1999;29:466-477.

10. Kaplan RM, Navarro AM, Castro FG, et al. Increased use of mammography among Hispanic women: baseline results from the NC Cooperative Group on Cancer Prevention in Hispanic Communities. Am J Prev Med. 1996;12:467-471.

11. Coughlin SS, Uhler RJ. Breast and cervical cancer screening practices among Hispanic women in the United States and Puerto Rico, 19981999. Prev Med. 2002;34:242-251.

12. Hayward RA, Shapiro MF, Freeman HE, Corey CR. Who gets screened for cervical and breast cancer? Results from a new national survey. Arch Intern Med. 1988;148:1177-1181.

13. Himmelstein DU, Woolhandler S. Care denied: US residents who are unable to obtain needed medical services. Am J Public Health 1995;85:341-344

14. Selvin E, Brett KM. Breast and cervical cancer screening: sociodemographic predictors among Whites, Blacks, and Hispanic women. Am J Public Health. 2003;93:618-623.

15. Ramirez AG, Talavera GA, Villarreal $R$, et al. Breast cancer screening in regional Hispanic populations. Health Educ Res. 2000;15:559-568.

16. Chavez LR, Hubbel FA, Mishra SI, Burciaga Valdez R. The influence of fatalism on self-reported use of Papanicolaou smears. Am J Prev Med. 1997; 13:418-424.

17. Hubbel FA, Waitzkin H, Mishra SI, Dombrink J, Chavez LR. Access to medical care for documented and undocumented Latinos in a Southern California county. West J Med. 1991;154:414-417.

18. Pérez-Stable EJ, Otero-Sabogal R, Sabogal F, McPhee SJ, Hiatt RA Self-reported use of cancer screening tests among Latinos and Anglos in a prepaid health plan. Arch Intern Med. 1994;154:1073-1081.

19. Goel MS, Wee CC, McCarthy EP, Davis RB, Ngo-Metzger Q, Phillips, RS. Racial and ethnic disparities in cancer screening: the importance of foreign birth as a barrier to care. J Gen Intern Med. 2003;18:1028-1035.

20. Hiatt RA, Pasick RJ, Stewart S, et al. Community-based cancer screening for underserved women; design and baseline findings from the Breast and Cervical Cancer Intervention Study. Prev Med. 2001;33:190-203.

21. Ramirez AG, Suarez L, Laufman L, Barroso C, Chalela P. Hispanic women's breast and cervical cancer knowledge, attitudes, and screening behaviors. Am J Health Promot. 2000;14:292-300.
22. Institute of Medicine. Unequal Treatment: Confronting Racial and Ethnic Disparities in Healthcare. Washington, DC: National Academies Press; 2003.

23. Martin LM, Calle EE, Wingo PA, Heath CW. Comparison of mammography and Pap test use from 1987 and 1992 National Health Interview Surveys: are we closing the gaps? Am J Prev Med. 1996; 12:82-90.

24. Ayanian JZ, Weissman JS, Schneider EC, Ginsburg JA, Zaslavsky AM Unmet health needs of uninsured adults in the United States. JAMA. 2000;284:2061-2069.

25. Breen N, Wagener DK, Brown ML, Davis WW, Ballard-Barbash R. Progress in cancer screening over a decade: results of cancer screening from the 1987, 1992, and 1998 National Health Interview Surveys. J Natl Cancer Inst. 2001;93:1704-1713.

26. Solis JM, Marks G, Garcia M, Shelton D. Acculturation, access to care, and use of preventive services by Hispanics: findings from HHANES 1982-84. Am J Public Health. 1990;80:11-19.

27. Suarez L. Pap smear and mammogram screening in MexicanAmerican Women: the effects of acculturation. Am J Public Health. 1994;84:742-746.

28. Singh GK, Siahpush M. All-cause and cause-specific mortality of immigrants and native-born in the United States. Am J Public Health. 2001;91:392.

29. Weinick RM, Jacobs EA, Stone LC, Ortega AN, Burstin H. Hispani healthcare disparities: challenging the myth of a monolithic Hispanic population. Med Care. 2004;42:313-320

30. Buekens P, Notzon F, Kotelchuck M, Wilcox A. Why do Mexican Americans give birth to few low--birth-weight babies? Am J Epidemiol. 2000:152:347-351.

31. Fuentes-Afflick E, Hessol NA, Perez-Stable EJ. Maternal birthplace, ethnicity, and low birth-weight in California. Arch Pediatr Adolesc Med. 1998;152:1105-1112.

32. Borraya EA, Guarnaccia CA, Differences in Mexican-born and U.S.born women on Mexican descent regarding factors related to breast cancer screening behaviors. Health Care Women Int. 2000;21:599-613.

33. Johnson HP \& Hayes JM. The demographics of mortality in California. Calif Counts Pop Trends Profiles. 2004;5:1-18.

34. Hiatt RA, Pérez-Stable EJ, Quesenberry C, Sabogal F, Otero-Sabogal $\mathrm{R}$, McPhee SJ. Agreement between self-reported early cancer detection practices and medical audits among Hispanic and non-Hispanic white health plan members in Northern California. Prev Med. $1995: 24: 278-285$

35. McPhee SJ, Nguyen TT, Shema SJ, Nguyen B, Somkin C, Vo P, Pasick R. Validation of recall of breast and cervical cancer screening by women in an ethnically diverse population. Prev Med. 2002;35:463473. 